\title{
An adaptive biomarker strategy clinical trial design
}

\author{
James Wason ${ }^{1}$, Nigel Stallard ${ }^{2 *}$, Janet Dunn ${ }^{3}$, Rob Stein ${ }^{4}$ \\ From 2nd Clinical Trials Methodology Conference: Methodology Matters \\ Edinburgh, UK. 18-19 November 2013
}

The Biomarker Strategy Design has been proposed for trials assessing the value of a biomarker in guiding treatment in oncology. In such trials, patients are randomised to a control arm, receiving the standard chemotherapy treatment, or a biomarker-directed treatment arm, when biomarker status is used to guide treatment. The randomised groups are then compared, often using a noninferiority test to assess whether the biomarker-guided therapy, limiting potentially toxic chemotherapy to a subgroup of patients, is at least as effective as universal chemotherapy.

Motivated by a current trial of biomarker guided adjuvant chemotherapy in breast cancer, we consider an adaptive version of this design in which two biomarkers are assessed. The trial is conducted in two stages. In the first stage, patients in the test-guided arm receive both a standard and a new test, with the standard test guiding treatment. An analysis comparing test results from this stage is then used to choose the test to use in the remainder of the trial, using the new test if the results for the two tests are sufficiently similar.

We used the delta method to approximate the joint distribution of the results from the two stages, showing that in practical situations the correlation between these is near zero. First stage results can therefore be used to adapt the trial without error rate inflation. We also show that for an appropriately chosen decision rule there can be considerable cost gains with only a small loss in power.

\section{Authors' details}

'MRC Biostatistics Unit Hub for Trials Methodology Research, Cambridge, UK. ${ }^{2}$ Warwick Medical School, University of Warwick, Coventry, UK. ${ }^{3}$ Warwick

Clinical Trials Unit, Warwick Medical School, University of Warwick, Coventry,

UK. ${ }^{4}$ Department of Oncology, UCL Hospitals, London, UK.

Published: 29 November 2013

${ }^{2}$ Warwick Medical School, University of Warwick, Coventry, UK

Full list of author information is available at the end of the article
doi:10.1186/1745-6215-14-S1-0103

Cite this article as: Wason et al:: An adaptive biomarker strategy clinical trial design. Trials 2013 14(Suppl 1):0103.
Submit your next manuscript to BioMed Central and take full advantage of:

- Convenient online submission

- Thorough peer review

- No space constraints or color figure charges

- Immediate publication on acceptance

- Inclusion in PubMed, CAS, Scopus and Google Scholar

- Research which is freely available for redistribution
() Biomed Central
C Biomed Central

() 2013 Wason et al; licensee BioMed Central Ltd. This is an Open Access article distributed under the terms of the Creative Commons Attribution License (http://creativecommons.org/licenses/by/2.0), which permits unrestricted use, distribution, and reproduction in any medium, provided the original work is properly cited. 